\title{
Iron Deficiency in Piglet and Economic Impact
}

\author{
Marco Vinícius Chaud* and Mariana Battaglin Villas Boas Alvaro \\ Department of Laboratory of Biomaterial and Nanotechnology. University of Sorocaba, Brazil
}

*Corresponding author: Marco Vinícius Chaud, Department of Laboratory of Biomaterial and Nanotechnology. University of Sorocaba, Brazil.

Received Date: October 10, 2019

Published Date: November 08, 2019

\section{Abstract}

The economic impacts in the production of porcine are negatively affected by iron deficiency in the piglets. The lower concentration of ironheme decreases the levels of haemoglobin in the bloodstream and, consequently, the oxygen distribution from lungs to tissue is damage. The anaemia due to iron deficiency is responsible for weight loss, an increase of parasitic, and infectious diseases. Many pharmaceutical and nutritional strategies have been adopted to minimize the financial losses of pig farming with a higher cost-beneficial, but the results are not satisfactory; they are mediocre. Better results could be achieved with haemoglobin-inspired pharmaceuticals capable of mimetic the iron- heme.

\section{Introduction}

Iron deficiency erythropoiesis and still further decreases produce anaemia that leads to abnormality in the levels of red blood cells around the body. It decreases the capability of these cells to carry on oxygen from the lungs to the tissues causes damages such as weight loss, immune deficiency associated with infectious disease. That causes significant mortality and high piglet refugee rate. In piglets, the anaemia by iron deprivation is the principal cause of prevalent iron deficiency, whose shortage of stored iron results mainly from a not programmed genetic selection [1].

The absence of haemoglobin as much as is necessary can be caused by iron deficiency, anaemia, liver disease, helminthiasis, infections, inflammatory bowel disease, and other diseases that vary depending on the severity of the piglet anaemia. On order hand, there is a high risk for the preventive treatment of iron deficiency, because of the high haemoglobin levels can be caused by heart failure, chronic obstructive pulmonary, and polyglobulia or erythrocytosis disease. The iron depletion and power ingestion during the early weaning period developing into a serious illness, between they the porcine circovirus (PVC-type 2), which is linked with growth retardation without overt clinical signs, lymphoid depletion, porcine dermatitis and nephropathy syndrome, and porcine respiratory disease complex [2,3]. So, it not easy to know the moment to use or not supplementary treatment of the piglet.
In 1963, Hunter showed that of a total of 656 piglets, those given ferrous sulphates by intramuscular (IM) route weighed $163,7 \mathrm{Kg}$ when weaned at two months, compares with 149,23 Kg for those given ferrous sulphate by oral route during the first two weeks of life [4].

Before 1963, in the middle of the twentieth century, [5]. 1955, announced an effective treatment for anaemia of piglets with a Fe-dextran preparation by IM route. In eight young anaemic pigs' haemoglobin was raised from 5.1 to $9.8 \mathrm{~g}$ per $100 \mathrm{~mL}$ within a fortnight after the first injection. This study showed ta higher bioavailability of Fe-dextran than Fe-phosphate [5].

An investigation of anaemia in piglets at weaning on postweaning constate that the prevalence of anaemia was associated with high ZnO (500mg. kg 1) concentration in nursery feed. Salt of cooper in the sulphate form is another mineral that could affect iron deficiency and anaemia in piglets. Both minerals were used as nutritional doses, respectively 500mg. kg-1 and 125mg.Kg-1 of feed [6].

We did not find studies that lead to the iron deficiency anaemia in piglets due to the poor bioavailability of iron by phytate complexion in the feed. The negatively charges phosphate in phytic acid binds to cations as $\mathrm{Fe}, \mathrm{Ca}, \mathrm{K} \mathrm{Mg}, \mathrm{Mn}$ and $\mathrm{Zn}$ making them insoluble compound, not bioavailable as nutritional factors [7]. 
Indeed, they do not have an efficiency solution until now for treatment or prevention of iron deficiency anaemia in the piglets.

\section{Economic Impact}

Iron deficiency invariably makes piglets more susceptible to infectious diseases and thus precedes virus infection by the porcine virus (PVC2), increasing the risk of epidemics. Iron supplementation is performed on commercial farms. However, the iron status of piglets is seldom evaluated. Therefore, it is imperative to reassess whether the routine iron supplementation protocols from products with a low cost-effective. Many researchers discuss the creation of a strain of modern piglets, more resistant to the undesirable effects of iron deficiency. Then could have health animal resulting in an increase of capability to resist infections, suppressed immune, parasitic disease, and have a faster growth rate and decrease morbidity and mortality [6,8]. However, the financial support of genetic modification is costly and time-consuming, and the risks of adjusting a new strain in different regions of a country or the world are both a challenge and a not inducement to research.

Allarcon, et al. used empirical data to model the cost of costweaning multi-systemic wasting syndrome per PCV2- subclinical infections at different farm severity levels. The economic tools used provided different types of information that are relevant to producers in animal health economics. However, the labour cost is usually classified as a variable cost, which can cause statistical bias when the income to the worker is paid for productivity. United King pig industry benchmarking data collected (Bench 09 and Bench 10 ) was estimated at $£ 52.6$ million per year (90\% CI: 34.7-72.0), and approximately $£ 88$ million per year during the PCV2 epidemic period 3.

\section{Looking past and Future Perspectives}

Many and different strategies have been utilized in the prevention and treatment of the iron deficiency in piglets. Among them the supplementation with iron is a common practice for the treatment and prevention of anaemia. For many decades, the preferred procedure for delivering iron supplements during early life stages has been through the intramuscular injection of a large amount of iron in the ferrous form, as the sulphate, citrate, fumarate. The complexed form with dextran, nitrosyl, polyamine, polysaccharides, EDTA and many other compounds. Treatment combined treatment with vitamins specially tua vitamin A and vitamin C. Supplementation with probiotics as living yeast (Biosaf), and Bac. licheniformis and Bac. subtilis (Bio Plus 2B), enzymes as phytase (Natuphos ${ }^{\circledR}$ ), enzyme complex (composed of enzymes targeted such as $\alpha$-galactosides and galactomannans). Iron amino acids chelate at glutamine, arginine, cysteine. Histidine, L-glutamic acid and L-serine [7,9-15].

Between all forms of presentation these that showed better performance were the iron amino acid chelate or complexed. However the effective cost is high for an effect slightly above the median level, and a good relative biological value but below ferrous sulphate. Better performance of amino acid complexes is better bioavailability and tolerance with adverse effects significantly lower than iron salts.

An unexplored approach is the complex coordination of amino acids or peptides that mimic iron-heme, the first work of investigation that better mimic heme iron was published in 2002 for human use. The authors make the reaction of coordination casein peptides with iron inspired in the iron-heme. This product showed the same relative biological value of the ferrous sulphate, with many times lower cost [16]. However, the taste (Fe) and odour (casein) were not pleasant for human use. After that Takeda et al., prepared a recipe for bread with the iron-casein complex masking both taste and odour [17]. So, this product could be used today by treatment and prevention of iron deficiency for humans and animals, especially the piglets.

\section{Acknowledgement}

None.

\section{Conflicts of Interest}

No conflicts of interest.

\section{References}

1. Szudzik M, Starzyński RR, Jończy A, Mazgaj R, Lenartowicz M, et al. (2018) Iron Supplementation in Suckling Piglets: An Ostensibly Easy Therapy of Neonatal Iron Deficiency Anemia. Pharmaceuticals (Basel) 11(4): 128.

2. Chen JY, Wu CM, Liao CM, Chen KC, You CC (2019) The Impact of Porcine Circovirus Associated Diseases on Live Attenuated Classical Swine Fever Vaccine in Field Farm Applications. Vaccine 37(43): 6535-6542.

3. Alarcon P, Rushton J, Wieland B (2013) Cost of Post-Weaning MultiSystemic Wasting Syndrome and Porcine Circovirus Type-2 Subclinical Infection in England - An Economic Disease Model. Prev Vet Med 110(2): 88-102.

4. Hunter AA (1963) Piglet Anaemie. Agriculture 38: 115.

5. Mc donald FF, Dunlop D, Bates CM (1955) An Effective Treatment for Anaemia of Piglets. Br Vet J 111: 403-407.

6. Perri AM, Friendship RM, Harding JCS, O Sullivan TL (2016) An Investigation of Iron Deficiency and Anemia in Piglets and the Effect of Iron Status at Weaning on Post-Weaning Performance. J Swine Heal Prod 24(1): 10-20.

7. Bohn L, Meyer AS, Rasmussen SK (2008) Phytate: Impact on Environment and Human Nutrition. A Challenge for Molecular Breeding. J Zhejiang Univ Sci B 9(3): 165-191.

8. Svoboda M, Drabek J (2005) Iron Deficiency in Suckling Piglets: Etiology, Clinical Aspects and Diagnosis. Folia Vet 49: 104-111.

9. Ashmead HDW (2001) The Absorption and Metabolism of Iron Amino Acid Chelate. Arch Latinoam Nutr 51 (Suppl 1): 13-21.

10. Egeli AK, Framstad T (1999) An Evaluation of Iron-Dextran Supplementation in Piglets Administered by Injection on the First, Third or Fourth Day after Birth. Res Vet Sci 66(3): 179-184.

11. Hertrampf E (2004) Olivares M Iron Amino Acid Chelates. Int J Vitam Nutr Res 74(6): 435-443.

12. Jiang JF, Jiang JB, Zhu H Sen, Jiang YQ (2009) Combined Treatment with Vitamin a and Iron to Prevent Piglet Anemia. Journal of Swine Health and Production 17(1): 22-27.

13. Richter G, Hartung H, Herzog E, Otto F (2006) Effects of Probiotic Feed Supplements on Piglets and Fattening Pigs. Tieraerztliche Umschau. 
14. Wang J, Li D, Che L, Lin Y, Fang Z, et al. (2014) Influence of Organic Iron Complex on Sow Reproductive Performance and Iron Status of Nursing Pigs. Livestock Science 160: 89-96.

15. Wei KQ, Xu ZR, Luo XG, Zeng LL, Chen WR, et al. (2005) Effects of Iron from an Amino Acid Complex on the Iron Status of Neonatal and Suckling Piglets. Asian Australasian Journal of Animal Sciences 18(10): 1485-1491.
16. Chaud MV, Izumi C, Nahaal Z, Shuhama T, Bianchi M, et al. (2002) Iron Derivatives from Casein Hydrolysates as a Potential Source in the Treatment of Iron Deficiency J. Agric. Food Chem 50(4): 871-877.

17. Takeda T, Carvalho Vila MMD, Sant Ana LL, Severino P, Balcao VM, et al. (2016) Development of Fortified Bread Using Peptide-Iron Chelate: A Perspective to Prevent Iron Deficiency Anemia. J Public Heal Asp 3(1):1. 